\title{
Heterogenesis in Musical Rewriting and (Re)Performance
}

\author{
Heterogênese na Reescrita e (Re)Performance Musical
}

\author{
Silvio Ferraz Mello Filho \\ Universidade de São Paulo \\ William Teixeira
}

Universidade Federal de Mato Grosso do Sul

\begin{abstract}
In the music of the Twentieth Century, Luciano Berio perhaps is one of the most concerned composers with musical rewriting, intercrossing several traditions, from either European music or traditional cultures. In a short text, Jürg Stenzl indicates the three forms of rewriting that Luciano Berio employs in his compositions: (1) the simple repetition of an original model; (2) the use of the original as an open field for experimentations and (3) the rewriting which exceed the limits of identity and anamorphosis of the original sonority until an unrecognizable situation. Musical writing is, therefore, crossed by a large set of music traditions, which can be used according to a "molécularization" process, closely related to the "allagmatic" concept developed by Gilbert Simondon. In this article we discuss the conceptual aspects of rewriting giving some examples from the practices in composition and performance.
\end{abstract}

Keywords: Musical rewriting, Berio, Molécularization, Allagmatic.

Resumo: Na música do século $\mathrm{XX}$, Luciano Berio é talvez um dos compositores mais preocupados com a reescrita musical, entrecruzando várias tradições, seja a música europeia ou a música de culturas tradicionais. Em um pequeno texto, Jürg Stenzl indica as três formas de reescrever que Luciano Berio emprega em suas composições: (1) a simples repetição de um modelo original; (2) o uso do original como um campo aberto de experimentações e (3) a reescrita que excede os limites de identidade e anamorfose da sonoridade original até uma situação irreconhecível. A escrita musical é, portanto, atravessada por um grande conjunto de tradições musicais, intimamente relacionadas ao conceito "alagmático" desenvolvido por Gilbert Simondon. Neste artigo discutimos os aspectos conceituais da reescrita dando alguns exemplos das práticas em composição e performance.

Palavras-chave: Reescrita musical, Berio, Molecularização, Alagmática. 


\section{History backwards, towards History}

Western Music has seen, since the Renaissance, movements where successive generations severed ties with their predecessors. On one hand, we have composers recalling an earlier musical tradition; on the other, the recollection of original songs, from the popular realm and from nature itself (birds, frogs, thunder sounds etc.). Following that tradition, we had Claude le Jeune (1530-1600) employing Greek scales (the chromatic mode) in Que'est devenue ce bel Oeil; Clement Janequin (1485-1558) adopting the shouting of street vendors of the Rue de la Harpe and of bird songs in Les cris de Paris and Le chant des oiseaux. And this tradition continued throughout the rest of Western Music History. In Romanticism, musicians looked back to the ruins of ancient Rome, the classical world; the neo-classics harken back to the world of classicism; and the neo-romanticism of the 1980s sought to return to Late Romanticism. In certain ways, this relationship between old and new reminds us of the tradition of loss, of a teleological man moving away from his origin, always believing he has lost something of its original force.

Contemporary Brazilian music - mainly that produced in São Paulo-has two composers, Gilberto Mendes and Willy Correa de Oliveira, as its reference points. They became well known in the 1970s and influenced the following generations of composers. Leaning on a strong background in European music, they induced a rupture with Brazilian nationalism; Mendes and Correa de Oliveira were very close to European avant-garde composers, among them - and in a particularly intense way, the composer Henry Pousseur. It is from Pousseur that Willy Correa borrowed the idea that every composition is a field of dialogues with the historical tradition. However, we need to raise the question: what European music are we authorized to encompass under this frame of historical tradition?

Considering this tradition, it is clear that we are dealing with a very specific and limited concept of history and culture. The critique of those limits was the aim of philosophers such as Foucault or Agamben. If already in the 1970s Eurocentric thought appeared controversial, today this way of thinking is still more subjected to critique. In the case of music, when we refer to practices from the past, we tend to think of the tradition of written music, understanding as their past the history of European written music. The old, in this sense, is what was written in a very specific past. The old was also registered in a very particular 
way, and it is now being read in the present by performers, composers, or analysts who possess the notational tools to understand it.

We take the risk of considering the old as only that old belonging to one history, being recycled or read again by the present that wishes to place itself within that same history. In this sense, the theme permits few elaborations, as any reading of whatever thing placed in the past is a current reading. To read a Partita by J. S. Bach, either printed or in digital format, is very different from what Bach had before him. The tempos are different, and to devalue such details is nothing more than the result of an ingenious reading of new lines of force that cross our ways of relating to things. New tempos, new densities, new network modalities; all of these interfere on each attempt to process the old. That is to say that there is no old. But there is the usual tradition that we consider diachronically as a history with continuous developments, or nonchronologically as a line of events from which we retain nothing beyond the representation of them, and where the continuities are constructions that we assemble on the surface of a universe that is in itself, at its most granular level, discontinuous.

But even accepting interpretations as "the new" and "the old," it is worth to reflect on the idea that, in a certain way, history impregnates itself in those that experienced it subcutaneously, from the time they sat in their desks at school to the time they experience more elaborate practices of a musical performance. Therefore, the idea of creating and thinking about music as an expansive field of dialogue - between composers, ages, people and sound expressions - attracts us.

\section{Berio, the rewriter}

In his work, above all from the 1980s onwards, Luciano Berio made use of the idea of composition as a field of dialogue, from which it expands beyond the written musical tradition and, indeed, beyond the western musical tradition. The repertoire with which Berio dialogues goes beyond that of Monteverdi (in Recital for Cathy), or the large set of oft-discussed and cited symphonic compsitions. Instead, it was in works such as Voci and Naturale that Berio entered into a broader dialogue with other traditions, such as the music of Sardinia. Also in Choral there are many references to the polyphonic techniques from Central Africa that he knew from the studies of Simha Arom. In a letter to Pousseur of 
January 10, 1966, Berio speaks about the polyphony of grammars, referring to a section of Votre Faust (De Bonis 2016, p. 201). ${ }^{1}$

What interests us in Berio is that his scope continues to pass through the sacred music of the West, observed in scores, but also pushes the boundaries of the field of dialogue towards a broader domain. He draws from elements that go beyond what can be converted into rhythm and melody, encompassing aspects of sonority and gestures related to specific musical practices with which he wants to engage. ${ }^{2}$

The challenge now is that a composer is no longer circumscribed by a written tradition. Other traditions have won a seat at the table. The reservoir of sonorities from which a musical composition can draw comprises the music of other peoples and, in fact, any kind of sound. Setting aside the limits of written tradition, we penetrate the sound itself. A sound may tell a story, speak of its past. The sound domain is clearly more multifaceted than music notation.

In this more open field of listening, we are always attempting to account for its most diverse modalities: (1) direct referentiality, (2) subsumed referentiality, or (3) total absence of an audible reference.

This led us to some modalities of compositional practice that we consider under the title of Rewriting:

1. Rewriting from whatever sound attracted our listening;

2. Rewriting from sonic or gestural materials, from musical practices of non-written cultural traditions;

3. Rewriting from historical materials of written tradition;

In a certain way, these modalities reflect Jürg Stenzl's proposition about Luciano Berio's practice of rewriting. According to Stenzl, the first modality of rewriting in Berio's composition would be that in which the composer identifies himself with something original: an original sonority, an original song, an original set of instruments, a specific sonorous ecology. In this first mode, both the composer's compositional interest and the way he blends sonorities and references is critical. The second modality consists of recovering these sonorities in order to experiment with them, either through analyses, time spent listening,

\footnotetext{
1 PSS-SHP - Korrespondenz mit Luciano Berio. Paul Sacher Stiftung, in Basileia. Apud, De Bonis, 2016.

${ }^{2}$ A case-study of this relationship in Berio's Sequenza XIV, namely with the music from Sri Lanka, as described in Ferraz and Teixeira, 2016.
} 
or examining details. The composer makes them a field of discoveries. Finally, in the third modality the composer overshoots the original, as he "abuses the original" (Stenzl 2001).

We would like to put this proposal of Luciano Berio side by side with the idea of Ritornello, defined by Deleuze and Guattari in the chapter "On the Ritornello," (in A Thousand Plateaus). It seems that the idea of Ritornello can help us to work inside the limit of free sonority, composition and performance, as steps related to the passage from the cycle of ritornellos of Chaos, to those of the Earth and those of the Cosmos. Three distinct forces: (1) forces of the ethereal unmaking and re-composition, without reference, the without-time; (2) the forces of affirmation of one place through the recurrence of legitimized traditions, the on-time; (3) and the allagmatic forces of the world's mixture and growth, directed to the simplest behavior of a body: its movement, its complex field of forces in motion, the out-of-time. ${ }^{3}$

In A Thousand Plateaus, Deleuze and Guattari associate these three aspects with three moments of artistic creation: (1) the artist defying chaos, seeking to give stability, some form, to fluctuating elements; (2) the artist giving continuous variation to this form and, last, (3) the artist going beyond the limits of the pair material-form to the realm of indistinct material-force, thus interweaving forces of diverse orders. ${ }^{4}$

If applied to music composition, these three moments, as described above, create an aperture that allows us to sustain both the forces we identify, either in geographic or historical terms, in the distance or as in the past, as well as the revising forces of musical and sound relationships, as an unrestricted experience. In a sense, the strategy we pursue here is to consider a musical object of the past, or from another culture, taking into account its figurative (key, sequence of chords, rhythmic and melodic structures), molecular (rhythmic structure, mechanisms of melodic linking, intervallic structure), and also its kinetic aspect (instrumental gesturing), to read it throughout the sound, connecting this cycle to performance.

\footnotetext{
${ }^{3}$ For more on the concept of allagmatic, see Simondon 2010, p. 559ff.

${ }^{4}$ For more on the concept of ritornello, see Deleuze and Guattari 1991a/b; Criton 2000; Ferraz 2011.
} 
It is important to remark that when using sound, we are not dealing with a simple pouring of colors into melodic or harmonic boxes. Considering sound is to bring any musical element to another musical listening, more related to the music happened after Twentieth Century wars. Such sonic-musical gestures allow us to create new gestures, and by borrowing some precepts proposed in Ferneyhough's texts, "Il tempo della figura" and "Form-figure-style: an intermediate assessment" (Ferneyhough 1993a, 1993b), or by Vaggione in “Objets, représentations, opérations " (Vaggione 1991), we can deepen in an allagmatic level.

We believe that, by transforming all elements in sonic-objects, we face a molecular transformation (molecularization), which renders more transparent any object. Once molecularized, productions related to distinct geographic places, cultures and time periods, and even trans-cultural elements and places, we are able to enter into a very important dialogue. In this sense, the music of the past has the same potentially creative gestures as does bird song, or musical instruments. It is what we call the heterogenetic of music rewriting.

\section{The practice of rewriting}

What we want to highlight is that the procedure of rewriting allows to work through the material and the ways of transforming and rewriting, having a highly heterogeneous material. Once more, we observe that the relationship with the past does not have so much to do with the search for a lost language or a connection with listening to produce a structural listening; rather, it simply constitutes a compositional poetic tool made by a package of divergent musical images crossed by a sound listening experience. In this sense, a fragment of past musical intonations continues to subsist, and these intonations (melodic, harmonic, rhythmic structures, combinations of timbre, musical gestures) are in conversation at a subcutaneous level in a given composition with another sound sources. It licenses a poetics which heterogeneity is opened to sound in the crossmodal aspects of listening: tactile, visual, proprioceptive and auditory. ${ }^{5}$

From the standpoint of composition, we can take the piece Passos de Manoel Dias as an example (Example 1). This piece is a rewriting of the motet Bajulans, composed by Manoel Dias de Oliveira, in the early nineteenth century. To do it,

\footnotetext{
${ }^{5}$ For a broader development of the cross-modal musical gesture, see Teixeira 2017, Chapter 5.
} 
it was taken into consideration an original recording of the small town were people sang this tune during a procession. This recording is traversed by many kinds of sound such as: dragging of foot, people murmuring and whispering, and other sonic images as if we were listening to the music out from the scene. Prados, the village were this sonic-scene was recorded, is located inside a group of mountains, and to listen to the village from one of these mountains is a singular experience. Then, we consider these sounds and the scraped sound of creaky wheels of an ox cart necessary to carry people from the neighborhoods to the ceremony.

Verônica Nadir, a piece for solo cello and string orchestra, was also written as a score palimpsest of the motets of Manoel Dias de Oliveira. Side by side with the written scores of the past, it was also put into use the soundscape of the procession, sounds from old recordings of the community, specific aspects on instrumental gestures, sounds of contemporary machines etc. Considering that the musicians for whom Verônica was composed lived in a small village where Dias de Oliveira's music is still played in the Good Friday processions, it was inserted in this piece fragments of quotations more or less clear, sometimes under a very strong anamorphosis or even entirely exposed through a simple harmonization and adaption for solo cello. Together with this reference material, other elements such as collage or transformations were crafted. Such is the case of the processions' matracas - which were used in the same way they were used in their original context - and of the superimposed rhythmic cycles of the church bells of Minas Gerais and the breathing sound of the dragging of foot in a procession, transformed into "breathing" cycles (Example 2).

The Motetos de Passos shares a similar provenience of the tune of Verônica, namely, Dias de Oliveira's catalogue of works. It was developed together with the leading voice through a process of suspensions and anticipations, in which each harmonic note was considered as a track whose duration is changed in a totally random way. Here, however, the aim was to create an anamorphosis by prolonging phrases, stacking them so that they slide over the others (Example 3). 


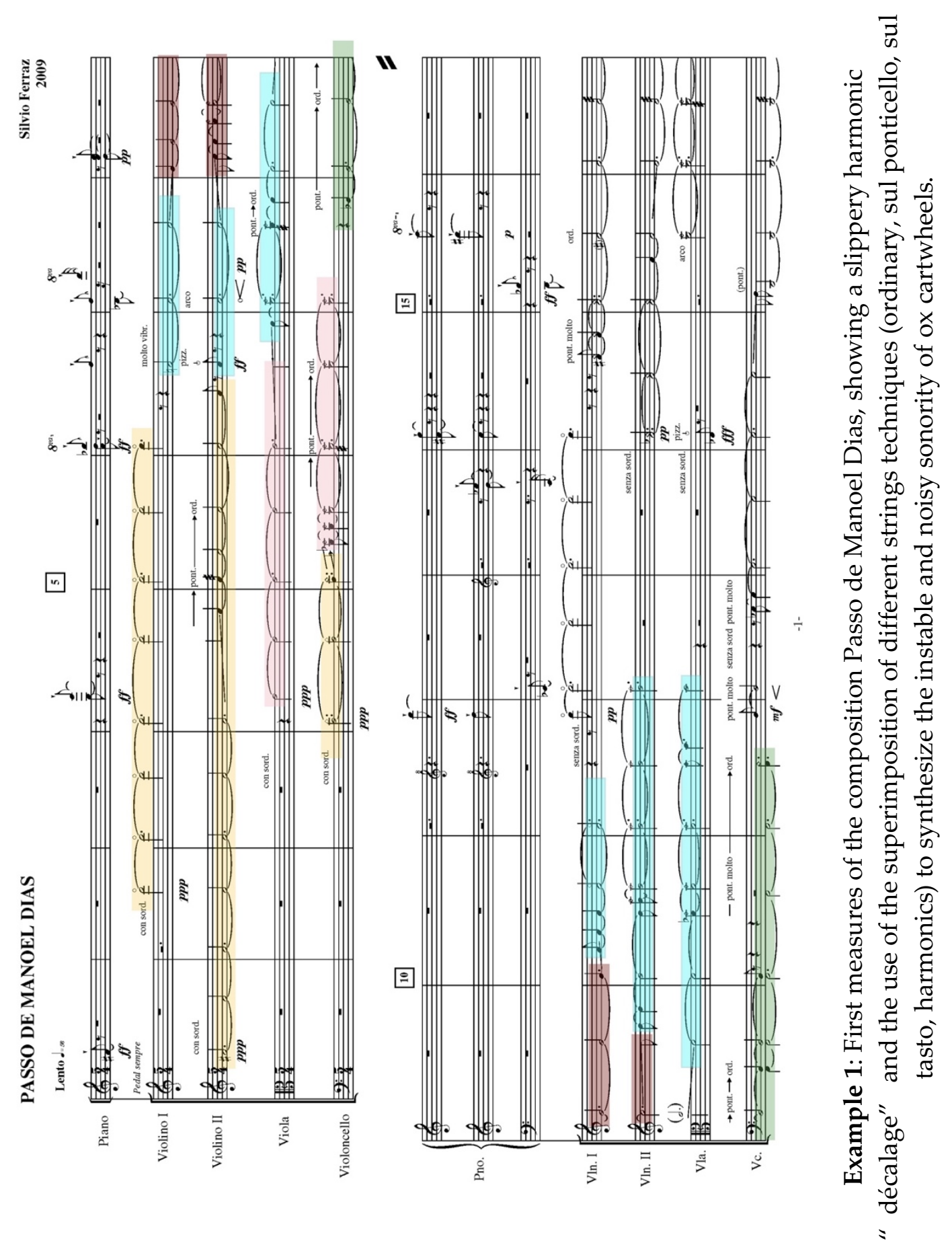


MUSICA THEORICA Revista da Associação Brasileira de Teoria e Análise Musical 2018, v. 3, n. 2, p. 189-202 - Journal of the Brazilian Society for Music Theory and Analysis @ TeMA 2018 - ISSN 2525-5541
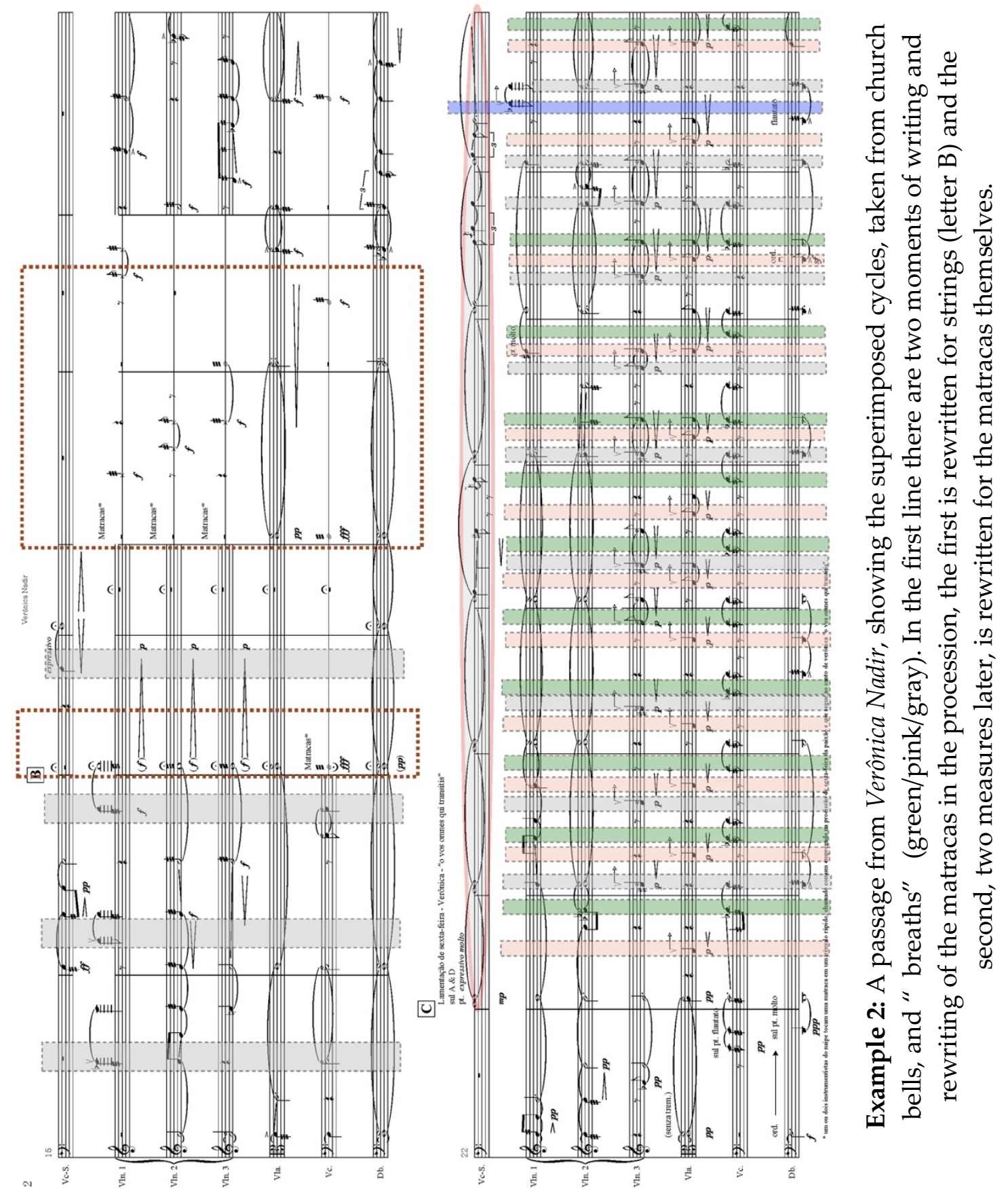


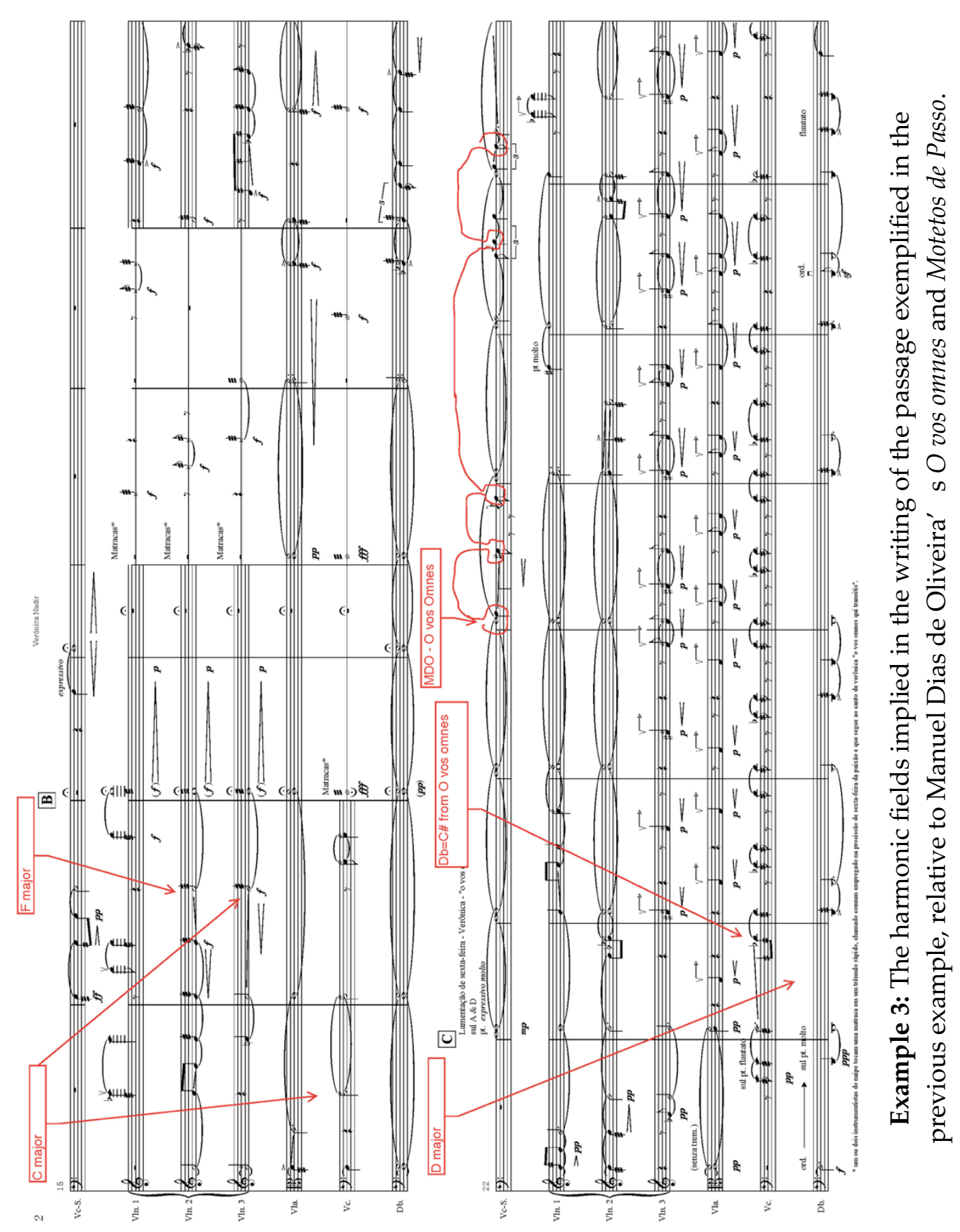

The piece ends with a simple presentation of $O$ vos omnes verbatim, as it were, in a version for solo cello. In this way, over the course of the piece, distinct modalities of rewriting are utilized. They range from the simplest and most direct, such as the rewriting at the end, to those that operate through anamorphosis and superposition. 
The last example is the Responsório ao Vento for solo cello and ensemble (Example 4). This composition has as a starting point a very open collection of materials: bird songs, harmonic passages from Vivaldi's violin concertos, the noise of boats in a harbor, and the gesture implied in some measures of the Prelude to Cello Suite no. 3 by J. S. Bach. To the point of no longer being easily recognizable, this original material is also fragmented and then re-fused through different procedures of fragmentation and anamorphosis. If the bird songs are merely emulated through a traditional solfeje, the measures of Bach's Suite functioned as a base for rewriting. However, not in conformity with the harmonic or melodic structure, but through the configuration of recurrent gestures in the writing for the cello. This configuration mirrors, in this case, a "listening" of the instrumental performance and not just a musical listening in the written sense of the musical notes. It is even possible to distinguish here in this selection how the sound, in the case of auditory emulation of the screeching of ox cartwheels, that can be easily compared, for instance, with the sound of a cello's pedal notes on a single string in counterpoint to higher notes made on the lowest string and produced in molto sul tasto (in this case, the bow's point of support should be placed in what would be approximately the tenth position for cello).



Example 4: Score of Responsório ao Vento, for cello and ensemble. Showing the emulation of screeching sounds from oxcart wheels; a rewriting of Bach bariolage; bird sons and internal responsiveness. 
For performance, those levels of heterogenesis do interest exactly in the sense they point to a world of movement and sound, since, as states the philosopher Nicholas Wolterstorff, the ethos of art is its world-projection attribute (Wolterstorff 1980). To play an 'ox-cart texture' means less a referential sort of meaning, as if 'the meaning of $x$ is $y^{\prime}$. Rather, what interests to performance is to enter that world of movement and sound, coming back to performance dirty of that earth, with a new world of possibilities, defying the tradition of performance practice and even the performer himself. It defies the performer to let down his prejudices and preferences to access, for instance, a harsh and nasty sound that demands an uncomfortable kind of movement, as the alto sul tasto requires. And this is, finally, the "existential meaning" (Polanyi 1962, p. 60) of a piece of music, the aim of an immanent hermeneutics.

To step over the footsteps of a Twenty-first Century composer means as much as to step over the footsteps of a Baroque composer for the performer. It is not a matter of restoring an intention or a divine inspiration, but a reterritorialization of space and time, since the same space in another time is another space. But this energy gives an impulse to the performer walking his own steps, not backward, but towards his ox-cart; his own direction that, finally, follows the energy that remains in the score and in the layers of human history realizations. This is how music finds its permanence, from tradition to tradition, or from composition to performance.

\section{4. (Re)marks}

Repurposing elements from the past, from other cultures, or from other sound sources implies operations that comprise what we call here as an allagmatic listening, on different levels of force and forms. To some extent, this remakes the way forward Simondon proposed as a mechanism for rising above the limited range of action possible at the superficial level of form and substance and that instead makes possible (1) an analytical operation of demodulation of form in its fundamental forces and (2) a syncretic operation of modulation, that pits one modular force against another. In this way we understand that rewriting has three moments: 
1. The conversion of the original model either as musical, sonic or gestural object;

2. The formulation of parameters for the object's analysis, already aware of potential developments;

3. A manifold synthesis of new objects through the analysis of the original's forces, namely:

a. Maintaining the referential relationship on the surface of listening (operation on the surface-level),

b. Maintaining the subcutaneous referential relationship (operation on the subcutaneous level but maintaining clear aspects of the surface),

c. Losing the referential relationship, but enabling the generation of new gestures (diving in the force level).

Finally, it is possible to state rewriting as the relationship with the music of the pasts, proposing compositional and performative acts which avail themselves of the most diverse tools to make a musical statement that permits the trip Deleuze and Guattari lay out in Ritornello: a free and recursive passage between Chaos, Earth and Cosmos. A movement between short and chaotic cycles (where forms are incomplete and ever-transient), the wheeling cycle of ordinary forms and substances and the titanic cycles of the cosmos (where our earthly cycles are just like grains). To travel freely through the universe of sound and energy, proposed by the post-1970s composers-above all by Ferneyhough and the spectralists - but without losing the bonds with the earth.

\section{References}

1. Criton, Pascale. 2000. On the purpose of a course on the 20th of March in 1984: Ritornello and Gallop, in Alliez, E. (org.) - Gilles Deleuze: A philosophic life. Rio: 34 .

2. De Bonis, Maurício. 2016. Berio e Pousseur, Correspondence and intertextuality, In: Meneses, Flo (org.). Luciano Berio: legacy and actuality. São Paulo: Edunesp.

3. Deleuze, G. e Guattari, F. 1991. Nous avons inventé la ritournelle. Nouvelle Observatoire, Paris.

4. Deleuze, G. and Guattari, F. 1980. Mille Plateaux. Paris: Minuit.

5. Ferraz, Silvio. 2011. La formule de la ritournelle. In: Revue Filigrane. Paris: Editions Delatour. 
6. Ferraz, Silvio; Teixeira, William. 2016. Técnica Estendida e Escrita Polifônica em Luciano Berio: Sequenza XIV. In: Meneses, Flo (org.). Luciano Berio: legacy and actuality. São Paulo: Edunesp.

7. Polanyi, Michael. 1962. Personal Knowledge: Towards a Post-Critical Philosophy. London: Routledge.

8. Simondon, Gilbert. 2010. L'Individuation a la lumiere des notions de forme et $d[$ information [1958]. Paris: Les editions de la transparence.

9. Stenzl, Jürg. 2001. La langue maternelle de Luciano Berio. In: CD, Berio-VOCI. Munique: ECM Records.

10. Teixeira, William. 2017. Por uma performance retórica da música contemporânea. Tese de doutorado, São Paulo: USP.

11. Wolterstorff, Nicholas. 1980. Works and Worlds of Art. Oxford: Oxford University Press. 